\title{
LEITURA NAS SÉRIES INICIAIS: ALGUMAS CONSIDERAÇÕES
}

\author{
B. G. Pereira*, A. N. ALENCAR** \\ Instituto Tocantinense Presidente Antônio Carlos (ITPAC)*, Faculdades Integradas Várzea Grande (FIAVEC)** \\ brunogomespereira_30@hotmail.com \\ Submetido em 30/04/2017 - Aceito 22/11/2017 \\ DOI: $10.15628 /$ holos.2017.5911
}

\section{RESUMO}

Este artigo artigo objetiva uma reflexão sobre a importância da leitura nos anos iniciais para a aquisição da linguagem e para formação de leitores com o hábito de ler desde o início de sua vida escolar. Considerando a leitura como um mecanismo indispensável no processo de aprendizagem e uma fonte inesgotável de pesquisa, recorreu-se a diversos textos para um apoio teórico para esta proposta de trabalho como as teorias de Vygotsky (1991), da Análise do Discurso, com Bakhtin (1929), e da Linguística Textual, Koch e Elias (2006) em Ler e compreender: os sentidos do texto, Aguiar e Bordini da Literatura: a formação do leitor: alternativas metodológicas (1998) dentre outros. Foram consultadas como embasamento a questão se a leitura é estimulada em sala desde sua apresentação pelo professor desde os primeiros anos escolar. É evidente que há uma grande falta de conscientização da sociedade sobre o papel da leitura em seus diversos contextos e também o quanto a mesma é essencial para desenvolvimento intelectual da criança em seus diversos aspectos e possibilidades.

PALAVRAS-CHAVE: Ensino de leitura; Anos iniciais; Concepções de leitura.

\section{READING IN THE INITIAL SERIES: SOME CONSIDERATIONS}

\begin{abstract}
This article aims to reflect on the importance of reading in the initial years for the acquisition of language and for the training of readers with the habit of reading from the beginning of their school life. Considering reading as an indispensable mechanism in the learning process and an inexhaustible source of research, several texts were used for theoretical support for this work proposal such as Vygotsky's (1991) theories of Discourse Analysis with Bakhtin (1929), and Textual Linguistics, Koch and Elias (2006) in Reading and understanding: the senses of the
\end{abstract}

text, Aguiar and Bordini of Literature: the formation of the reader: methodological alternatives (1998) among others. The question was asked whether the reading is stimulated in the classroom since its presentation by the teacher since the first school years. It is evident that there is a great lack of awareness of the society about the role of reading in its different contexts and also how much it is essential for the intellectual development of the child in its various aspects and possibilities.

KEYWORDS: Teaching reading; Initial years; Conceptions of reading. 


\section{INTRODUÇÃO}

No presente artigo busca-se analisar questões relacionadas à leitura, ressaltando, assim, sua importância para nortear algumas metodologias que o professor de série inicial possa utilizar para apresentar a leitura aos seus alunos de modo positivo.

Na perspectiva em que a leitura não é um hábito fora do ambiente escolar, a maneira que a leitura é apresentada aos alunos ao logo dos anos iniciais do Ensino Fundamental pode resultar na falta de estímulo, pois as concepções que norteiam as práticas docentes podem formar leitores competentes como também valorizar aspectos que influenciem negativamente e desmotivar o aluno.

Contudo, é indispensável que o professor reflita sobre suas concepções de leitura, focando sempre em um resultado positivo, buscando metodologias voltadas para estimular o gosto pela leitura, conscientizando seus alunos da importância da leitura para seu crescimento intelectual, social e profissional.

\section{CONCEPÇÕES DE LEITURA}

As práticas sociais e discursivas do ser humano tem sido opção de investigação para muitos pesquisadores, principalmente o uso da linguagem na experiência do relacionamento humano como sua prática social mediadora, fruto da filosofia de Bakhtin (1992). Para o autor, os signos como a linguagem é um importante mediador da interação humana com o meio em que vive. As teorias de Bakhtin(1992) levam a questionamentos sobre o papel da linguagem na construção do sujeito e formação da consciência a partir da interação com o outro.

De acordo com Koch e Elias (2006, p. 9-12), há três concepções de leitura, focando no autor, no texto e na interação autor-texto-leitor. 
A primeira concepção de leitura é compreendida como um simples processo de captação de ideias: o texto é visto como um produto acabado - lógico - do pensamento do autor. Nessa concepção, a leitura é apenas um ato de decodificação do código linguístico, ou seja, o leitor se limita ao domínio lexical, sem recorrer a seus conhecimentos prévios para entender o que está dito no texto.

Subjacente a esta concepção de texto e leitura, está uma concepção de língua como representação do pensamento de um sujeito. Nesta concepção, o foco da leitura está voltado para o autor e suas intenções, e o leitor desempenha apenas um papel passivo de captar as ideias do texto.

A segunda concepção de leitura é representada como uma atividade de reconhecimento do sentido das palavras e estruturas do texto, este é visto como um produto da codificação de um emissor e de codificação de um receptor, bastando para isso que este último conheça o código linguístico utilizado. Nesta concepção, pressupõese a língua como estrutura, como código linguístico. O leitor é o único interventor na atividade da leitura, sendo ele que constrói o sentido da mesma a partir de seus conhecimentos prévios.

A terceira concepção tem seu foco direcionado para a interação autor-textoleitor. A leitura é vista como uma atividade complexa de produção de sentidos. Nesta perspectiva, a língua tem uma natureza interacional - dialógica - e, ao contrário das duas anteriores, os sujeitos são ativos, e o sentido do texto é construído na interação textosujeitos. Com isso, a leitura é compreendida como uma atividade de interação entre sujeitos, onde o texto é uma unidade de sentido tanto para o autor dizer, quanto para o leitor entender o que foi dito.

Ainda que haja, porém, lugar para uma gama de sentidos implícitos e interpretações nesta concepção de leitura, a produção de sentido é baseada nos elementos da superfície textual, na sua forma de organização e requer, também, a mobilização do conjunto de saberes inerentes ao processo comunicativo. 
As concepções de leitura variam conforme a visão da pessoa, de língua, texto e também de sentido. Koch (2006) afirma que à concepção de língua como representação do pensamento corresponde a do sujeito, individual dono de suas vontades e ações. A leitura é entendida como atividade de captação das ideias do autor sem levarem conta as experiências e os conhecimentos do autor.

A leitura, portanto, é um processo no qual o leitor realiza um trabalho de interpretação e compreensão do texto. Baseando-se no seu conhecimento sobre o assunto, trata-se de uma atividade que necessita de estratégia de seleção, antecipação e verificação.

A concepção de leitura que norteia este trabalho é aquela que dirige seu foco para a interação, pois, conforme Koch e Elias (2006), a leitura é uma atividade de produção de sentidos baseada na interação autor-texto-leitor.

Pode-se, com isso, ressaltar que, mesmo construída na interação, a produção do sentido deve ser feita levando em conta não só os conhecimentos do leitor, como também o estilo próprio do texto que guia a leitura.

A criança, ao brincar, manifesta tudo o que lhe chama atenção, que causou profunda impressão. É através de brincadeiras que a criança expressa sua experiência de vida, seu sentimento, sua maneira de ver o mundo. Com isso, pode-se deduzir que a leitura é vista por ela como uma brincadeira que pode leva-la a observar, experimentar, investigar e imitar, dando sentido e reconstruindo seu mundo e o mundo que a cerca.

Durante a vida escolar não é difícil percebe-se que a leitura por várias vezes é imposta para o aluno como uma exigência para uma atividade avaliativa ou para responder questões levantadas pelo professor cuja resposta está no texto. Lê-se para procurar respostas, não para construção de sentido a partir de conhecimentos prévios, com isso podemos ver que a leitura tem sido apresentada de maneira equivocada.

É comum os professores apresentarem um considerável despreparo quanto à abordagem da obra literária, o que pode direcionar o aluno a um total desinteresse pela leitura, que pode comprometer negativamente todo o processo de aquisição da leitura, que é um processo complexo e delicado. 
No caso do ensino de leitura nos anos iniciais é comum testemunhar-se a utilização de atividades meramente mecânicas, como cobrir, copiar e decodificar. Segundo Angela Kleiman (1993 apud MENEGASSI; CALCIOLARI, 2002, p. 82), "as práticas de leitura como decodificação não modificam em nada a visão de mundo do leitor, pois se trata apenas de automatismos de identificação e pareamento das palavras do texto com as palavras idênticas em uma pergunta ou comentário". São práticas que precisam ser extintas das aulas de leitura para o sucesso da aquisição e domínio da linguagem ao logo nos primeiros anos escolar.

\section{LEITURAS NAS SÉRIES INICIAIS}

Proporcionar a criança o conhecimento do mundo encantado da leitura é um dos papéis fundamentais da escola. Isso é possível por meio dos clássicos infantis, contos, lendas, anedotas, quadrinhos, dentre vários outros. Para isso, é indispensável que os professores sejam os elementos de ligação entre os alunos e a leitura, incentivando-os a gostar do mundo de fantasia, ampliando, assim, o potencial imaginativo da criança.

Existem várias formas de incentivar a criança a gostar de ler, bem como a criar o hábito de leitura. Ser um bom contador de histórias é uma dessas formas, pois as crianças se encantam com o professor, com a entonação de sua voz, os gestos, as caras e bocas, os risos ou choros, enfim, tudo aquilo que traz emoção para o momento. E mais tarde tentam imitá-lo agindo da mesma forma.

O primeiro passo para a formação do hábito de leitura é ofertar textos próximos à realidade do leitor, que tenha significado para ele. A sintonia do leitor com a obra estimula a predisposição para leitura e resulta no ato de ler e consequentemente o gosto pela leitura, pois o aluno somente terá habilidades de leitura se tiver primeiramente o hábito de ler. 
A literatura pode dar prazer quando tem seu fim em si mesma, e não está subordinada a um objetivo prático imediato imposto pelo professor. A criança tendo o devido estímulo à literatura, pode dar vazão a seus sonhos, a sua imaginação e criatividade. Para que essas motivações continuem, a escola deve produzir um ensino eficiente de leitura, tentando cumprir com seu papel social de maneira eficaz com requisitos básicos como: biblioteca rica em variedade literária, professores preparados teoricamente, com metodologias inovadoras e atraentes que valorizem literatura.

O texto deve ser o ponto de partida e ponto de chegada ao processo de aprendizagem da leitura. Ao ler, ativa-se todo o repertório cultural da criança, sistema de valores, crenças e atitudes. Essa dinâmica interacional implica conhecimentos prévios que são fundamentais à constituição dos sentidos do texto. Para a leitura do texto literário, enfatiza-se o Método Recepcional, organizado por Aguiar e Bordini (1998), a partir dos pressupostos teóricos da Teoria da Recepção, de Jauss (1994). O trabalho com o texto literário deve orientar-se, de maneira dinâmica, do simples para o complexo, do próximo para o distante no tempo e no espaço para ampliar o horizonte de expectativa do leitor.

\section{POSSIBILIDADES DE ENSINO}

Existem diferentes caminhos para ensinar a ler. Para um grupo de educadores, o aluno deve partir das pequenas unidades da língua, como as letras e os fonemas, passando em sequencia, por sílabas, palavras e frases. Para outros, é exatamente o contrário: o aluno é capaz de entender um bloco de texto antes de perceber as partes que o compõem. É o caminho inverso, os alunos partem de textos inteiros para só depois analisar as unidades menores da língua, enfatiza Soares:

Durante muito tempo a alfabetização foi entendida como mera sistematização do " $B+A=B A$ ", isto é, como a aquisição de um código fundado na relação entre fonemas e grafemas. Em uma sociedade constituída em grande parte por analfabetos e marcada por reduzidas práticas de leitura e escrita, a simples consciência fonológica que permitia aos sujeitos associar sons e letras para produzir/interpretar palavras (ou frases curtas) parecia ser suficiente para diferenciar o alfabetizado do analfabeto (SOARES, 2003, p. 125). 
De acordo com os estudos da área da linguística percebe-se que não se constrói leitores por meio do ensino mecânico. A língua é um fenômeno social, dinâmico, vivo e mutável, não funciona sempre do mesmo jeito, ela muda de acordo com o contexto, a situação de produção e a intenção do interlocutor. Portanto, a aprendizagem não significa repetir modelo pré-determinado, mas a capacidade de fazer uso da linguagem em diferentes situações de comunicação, usar a língua para seus variados fins.

Aulas expositivas e exercícios escritos e orais de interpretação são praticados pela maioria dos professores, o que também promove a falta de incentivo e de motivação dos alunos para a leitura. Esses profissionais valem-se, muitas vezes, de atividades repetitivas, com total obrigatoriedade, satisfazendo-se com a simples leitura dos textos solicitados por meio das "fichas de leitura"; isso faz com que a criança perca completamente o prazer pela atividade proposta, pois a cobrança do texto solicitado é extremamente clara ao aluno.

A cada leitura, os alunos precisam responder as atividades de gramática e redação, sem qualquer relação com o caráter artístico de um texto literário. Os professores não oferecem atividades, nem utilizam recursos que permitam a expansão dos conhecimentos dos alunos, das suas habilidades intelectuais, da sua criatividade ou da sua tomada de posição. Com isso, a livre discussão e o debate são esquecidos.

Segundo Aguiar e Bordini (1988), um modelo de aula de leitura, em algumas escolas brasileiras, poderia ser descrito como uma sequência de atividades mais ou menos estáticas: apresentação de um texto, explicação do vocabulário, exercícios de interpretação, exercícios gramaticais e composição.

Para que isso seja evitado, devemos levar em consideração que a leitura pode aproximar-se das atividades lúdicas em geral, tendo como uma de suas finalidades é provocar a emoção e a diversão do leitor, sem oferecer-lhe vantagens materiais. 
De acordo com as autoras citadas (1988), mesmo sem obrigatoriedade, a "brincadeira" não é, entretanto, um ato incontrolado, mas estruturado a partir de regras às quais o indivíduo deve se submeter. A literatura também tem esse mesmo caráter, uma vez que, ao elaborar a sua obra, o autor institui normas e regras de composição, fornecendo indicadores de leitura, os quais o leitor segue com o criador.

Ainda, segundo as autoras supracitadas, podemos ter o exemplo de uma aula, nas séries iniciais, em que o conteúdo é "brincadeiras com linguagem" e o objetivo é "proporcionar à criança possibilidades de desenvolver seu potencial linguístico". Por exemplo: o professor, através de observação do comportamento verbal da turma, em várias ocasiões, percebe que as crianças (ou algumas delas) têm dificuldade em reproduzir histórias e criar novas situações a partir das narrativas lidas.

Para conscientizar os alunos dessa carência, o professor propõe uma brincadeira intitulada "Quem quiser que conte outra". Ele conta uma história omitindo o final e pede que os alunos a reproduzam oralmente, inventando um desfecho criado por ela. Depois disso, retoma a história, levando-os a relatar os fatos principais com base nas ilustrações, e lê o final. A seguir, discute com a turma quais as diferenças entre as versões dos alunos e a conclusão original.

A participação do adulto (pais e professor) pode enriquecer e legitimar a experiência de leitura da criança, estimulando sua criatividade, sua paciência, serenidade e concentração que poderão contribuir para a formação de um ótimo profissional, ressignificando papéis sociais, costumes e valores, vendo a vida exatamente como ela desejaria que fosse.

Ao ver seus pais lendo, é comum reagir querendo imita-los no que para a criança é uma brincadeira, ela imita modo segurar, tom de voz e expressão facial, faz experiência se esse for um hábito de sua vida diária, pois, são as experiências diárias que aguçam sua curiosidade. Ler juntos reforça laços afetivos, as crianças gostam muito quando o adulto lê com ou para elas, pois se sentem mais valorizadas legitimando seu mundo. 
A brincadeira é uma situação imaginária criada pela criança e onde ela pode, no mundo da fantasia que será de acordo com sua criatividade, satisfazer desejos até então impossíveis para a sua realidade. Ao se encontrar totalmente absorvida pelo o encantamento que a leitura pode lhe proporcionar é um momento mágico e precioso para a criança, no qual ela estará adquirindo o hábito e o gosto pela leitura, exercitando a capacidade de construir sua identidade se consolidando como sujeito. 


\section{CONSIDERAÇÕES FINAIS}

De acordo com o que foi exposto, percebe-se que o professor precisa de uma boa formação teórica sólida para embasar sua prática, entender a natureza da língua escrita, como se dá a sua aquisição pela criança, para poder, interferir, mediar e respeitar o processo de construção na fase inicial da aprendizagem.

Muitas vezes, por falta de conhecimento, o professor culpa a criança pelo seu baixo desempenho na aprendizagem da leitura, atribuindo a sua suposta deficiência linguística e cultural. Entretanto, a dificuldade não está na criança, mas na escola que não consegue desenvolver as habilidades necessárias para ela domine a língua padrão.

Outra questão que precisa ser levado em conta, é que, a criança que não têm prática de leitura em seu meio cultural fica em desvantagem diante daqueles que vivem em um ambiente letrado, e o professor precisa, portanto, propiciar em sala de aula um ambiente onde essas crianças possam vivenciar situação real de uso da linguagem, levando a consumir, produzir e entender sua função e funcionamento.

A partir dos estudos de Ferreiro (2001) e Luria (2006) sobre a construção da linguagem das crianças, os educadores têm mais condições de oferecer um ensino eficaz e superar as concepções equivocadas. Esses autores tratam do mesmo tema, mas com perspectivas e concepções diferentes. Ferreiro fundamenta-se em Piaget (1977) que vê o sujeito biológico, centrado no seu eu no processo de construção do conhecimento.

O conhecimento é o resultado de uma construção mental construída a partir da interação do sujeito com o objeto de conhecimento. Já Luria e Vygotsky entendem que o conhecimento é uma construção mental construído na interação da criança com o outro e o objeto, mediado pela linguagem, a linguagem e o outro tem um grande papel, são fundamentais na construção da leitura e escrita da criança.

Nesse sentido, Ferreiro com sua teoria psicogenética da língua escrita, estuda a criança como um ser universal que, levanta hipótese sobre a escrita, ou seja, todas as crianças passam pelo desenvolvimento da escrita numa ordem determinada. Para Luria, a criança é um ser social único que constrói de forma diferente o saber e a aprendizagem está relacionada com o meio social, cultural em que ela vive. 
Apesar das diferenças, Ferreiro e Luria têm muito em comum, ambos veem a criança com construtora de conhecimento, porém cada um olha por um ângulo, um ponto de vista diferente. Luria na perspectiva sócio-histórica. Ferreiro, a partir do eu biológico. A diferença de concepção de aprendizagem entre ambos têm implicações no ensino e aprendizagem da língua escrita.

A perspectiva interacionista, enfatiza e defende a presença do outro no processo da aprendizagem, ressalta a importância de se trabalhar a leitura e escrita com prática discursiva e dialógica. Assim, "a criança aprende a ler e escrever, com, e para o outro, e se apropria dos conceitos, elabora o discurso interior, aprende a falar e dizer o que pensa pela escrita" (SMOLKA, 2003). Como se pode perceber, falar em leitura, na fase inicial, significa falar em formação competente do professor para atuar nessa fase. Apontada como uma das maiores deficiências em muitas pesquisas com os alunos brasileiros, 0 ensino de leitura precisa ser repensado na escola, precisa-se rever metodologias de ensino da linguagem, seus significados e objetivos, quais fatores estão levando a esses dados e buscar soluções para sanar tais deficiências.

A interlocução professor-aluno-escola-formação dá a medida certa, nesse momento, para a formação de leitor proficiente desde os anos iniciais do ensino fundamental. É extremamente importante a escolar lançar mão de mecanismos que possam assegurar o domínio das habilidades e o hábito da leitura, pois necessitamos cultivar este hábito entre as crianças, com o auxilio da escola para garantir a formação de leitores competentes que faça uso da língua de maneira consciente e eficaz.

\section{REFERÊNCIAS}

Aguiar, V. T.; Bordini, M. da G. (1988). Literatura: a formação do leitor: alternativas metodológicas. Porto Alegre: Mercado Aberto.

Bakhtin, M.; Volochinov, V.N. (1995). Marxismo e filosofia da linguagem. Trad. Michel Lahud; Yara Frateschi Vieira. 7. ed. São Paulo: Hucitec.

Ferreiro, E. (2001). Reflexão sobre alfabetização. 24. ed. São Paulo: Cortez.

Jauss, H. R. (1994). A história da literatura como provocação à teoria literária. Trad. de Sérgio Tellaroli. São Paulo: Ática. 
Koch, I. G. V. (2002). Desvendando os segredos do texto. São Paulo: Cortez.

Koch, I. G. V.; Elias, V. M. (2006). Ler e compreender: os sentidos do texto. São Paulo: Contexto.

Menegassi, R. J.; Calciolari, A. C. (2002) A leitura no vestibular: a primazia da compreensão legitimada na prova de Língua Portuguesa. Maringá: UEM - Acta Scientiarum, v. 24, n. 1, pp. 8190.

Smolka, A. L. B. (2003). A criança na fase inicial da escrita: Alfabetização como processo discursivo. Ed. São Paulo: Cortez.

Soares, M. B. (2002). Letramento: um tema em três gêneros. 2. ed. 5. reimpressão, Belo Horizonte: Ed. Autêntica. 